\title{
Digital transformation of personnel management services
}

\author{
Olga Osipova \\ The Department of Sociology, History and Philosophy \\ Financial University under the Government of the Russian \\ Federation, \\ Moscow, Russia \\ ORCID https://orcid.org/0000-0002-4111-0391
}

\begin{abstract}
The present paper analyses the extent of development of digital maturity of organizations and HR processes in the transport-logistics field. Digitization is studied in a broader sense as a process of transition from traditional organization into a digital one. The paper presents the author's classification of digital transformation of a traditional organization into digital, and includes six possible potential levels of digital maturity at present time, as per the degree of automation of production and organizational processes. Based on a sociological survey data, a subjective view of specialists from HR services in the transport-logistics economic sector is presented; this view allows us to understand the depth of digitalization processes in HR departments and the organizations as a whole. The conducted analysis showed that the extent of automation of HR processes in transport and logistical organizations is lower than the extent of automation of main HR processes. At the same time the respondents have highly appreciated the extent of integration of main HR processes. The survey results have shown a higher extent of integration of $H R$ processes and a better-defined strategic approach in the work with personnel of transport-logistics organizations, as compared to data of all the respondents. The conducted survey enables us to make specific perspective actions which would make it possible to recalibrate automation of HR processes in the transport-logistics sector of economy. The increasingly larger role of HR management is proved in the context of deepening gap between the speed of technological growth and the productivity of business.
\end{abstract}

Keywords - HR management, personnel management, digital economy, digital organization, digitization, automation of $\mathrm{HR}$ processes, Digital maturity of $\mathrm{HR}$ processes

\section{FUNDING}

The reported study was funded by RFBR, project number 19-010-01042\19

\section{INTRODUCTION}

The new technologies are rapidly rushing into our lives. These are data analysis, sensors, artificial intelligence, machine learning, cognitive computations and digitization. The speed with which new technologies are spreading is dictated by state-sponsored projects on digitization of the economy in different sectors; the transport sector, in particular. According to the document titled "The development strategy for information-based society of the Russian Federation (RF) for the years 2017- 2030", Russia must solve the problem of transformation to digital economy. This term has to be understood in the sense of economic activities where a key factor for production is the availability of data in digital form [1]. The Program "The digital economy of the Russian Federation" concretizes that a salient feature of the digital economy is the availability of data in digital form, and which is the key factor for production in all the sectors of social and economic activities. This ensures an effective interaction between the state, business and the society [2].

The concepts of 'digital economy' and 'digitization' ('digitalization') are inseparable. Even the Google search system defines the term digitalization as transformation of information into the digital form. The meaning of the term digitization in a narrow sense and a broad sense must be differentiated. The term digitization (in the narrow technical sense of the word) implies transforming information from the analogue form to the digital form [3]. In management, it is necessary to study digitization in the broad sense of the term as a long-term process, leading not only to technical changes. "The digitization is neither a technology nor a product. It is rather an approach in using digital resources for transformation of works in an organization, as noted by Kerravala Consulting Group in their study. The digitization implies redefining technologies and business processes in order to improve the working environment of personnel, and also interaction with customers and other participants in the activities of modern distribution companies. Digitalization significantly improves company's productivity and coverage" [4]. In our view, the digitization (in the broad sense of the word) must be regarded as a process for transforming a traditional company into a digital one. This process is directly linked with the notions of 'automation' and 'computer software' (CS). But these are not the only notions it leads to. The digitization process assumes significant organizational changes; in switching over to a new architecture of the organization itself and in making cardinal changes in the functioning of internal and external channels of communication as well as qualitative transformation in HRtechnologies. 
For the past two-three years, a lot of discussion regarding digital transformation is going on. But this discussion, in fact, started about two decades back, with the advent of Internet 1.0. Internet has greatly influenced the way we communicate with each other, and also impacted our work culture. It has visibly transformed many sectors, and has had a huge impact on our life [5]. All the experts agree that these changes will be much more intensive, thanks to the emergence of Internet 2.0 and universal connection to it (like the Internet of Things, smart homes and cars etc.); a new system of financial exchange (blockchain); and breakthrough in the field of Information Technology (IT) (like artificial intellect, augmented reality). All the technologies just mentioned will find, in the near future, their applications in various sectors, and will completely alter the way the business is conducted today.

According to the data released by IDC, the Internet of Things (IoT) is being actively used in several sectors in Russia, such as production, transport and energy sector. These sectors account for more than $50 \%$ of volume generated for the IoT market. In particular, the monitoring of cargo-carriers is based on using radio frequency wave identification technologies REDS, GPS, GRPS and Geographical Information System (GIS) for the creation of an intellectual transport system that performs monitoring of the location, routes, and also conditions under which the cargo is being transported in real time by means of wireless or satellite or any other means of communication. The production and transport sectors remain the leading sectors for investments in the IoT [6]. According to the analysts of The Boston Consulting Group, among the sectors transport and logistics services occupy the third place as per importance, and are the one where significant digital changes are likely to occur. The use of the IoT in the transport sector will continue its growth thanks to the digitization of the sector as a whole, and due to application of advanced practices which are being introduced by the leaders of the sector as well as by standard-bearers of the banking sector [6,7].

Thus, the leading role of transport and logistics in the digitalization of Russian society is beyond doubt. Hence researchers in the field of the organizational management have a special interest in the study of leading organizations of this sector of the economy. The most significant, and, at the same time, the least studied questions are those related to reorganization of HR-services of transport companies, and specially perception and evaluation of given processes by the HR-specialists themselves. Therefore, it is no coincidence that the objects of study in this article are precisely the organizations of transport and logistics.

The rapid technical progress and reduction in time gap between discovery and introduction of technical innovations in production give rise to many new organizational problems. At present the experts, including the consultants of Deloitte Company, note an increasing gap between the speed of technological development and productivity of the business [8, 9]. What is the reason of this increasing imbalance? In a survey carried out in the beginning of 2018, the leaders of
Russian industrial enterprises were asked about the factors that created obstacles in successfully introducing industrial IoT in Russia. The results were as follows:76\% of those surveyed stated high cost of projects, for $69 \%$ it was un-preparedness of personnel, non-understanding by managements and owners: $66 \%$, non-development of suggested technical solutions: $59 \%$, underdeveloped infrastructure: $31 \%$, while $25 \%$ of those surveyed stated complexities of integration were the reason, and for $20 \%$ it was the absence of standards [10]. Alexander Smirnov, Director of Data Science, Teradata Company in Russia, notes: "We can confidently state that the complexities of technical nature now do not arise because all the necessary instruments from the point of view of information systems already enable us to solve almost all problems of any complexity, we often see organizational difficulties based on project experience of our company" [11].

Thus, the un-preparedness of personnel and complexities of organizational nature are the principal reasons for causing increasing gap between development of technologies and productivity of the business. Since the managerial services personnel is directly concerned with the problem of organized development and preparing personnel for innovations, the activities of HR-services become a systemic function of the company, when it transits from being a traditional company to a digital one. On the one hand, a people management system can give an impetus to business growth and facilitate its transition to a new qualitative level, including new business development models. On the other hand, the digitization creates principally new possibilities for management of the human resources service of the organization.

The HR-service may help the business close the abovementioned gap, and reduce the time taken for adapting to technological and organizational changes in the organization. But for this to happen, the HR-technology and management of personnel service itself must undergo major changes. Those organizations, which are standard bearers of the economic development 4.0, are actively seeking for not only new business models and flexible organizational forms, but also new non-standard methods of organizing work with personnel .However, this work is yet to receive scientific comprehension, and this hampers to a great extent the adaptation of new knowledge to the domestic economy and makes it necessary to urgently conduct our own scientific reflexes in the field of HR-management.

The following problems need urgent attention for investigation:

How do HR-specialists evaluate the process of transformation of transport-logistics companies into digital companies?

How does digital transformation in the field of logistics and transport differ from Pan-Russian indices?

How do processes of human resources management are changing; how mature is automation of HR-processes? 
How do the HR-managers, working in the transportlogistics sector of the economy, view the future of personnel management service?

\section{Purpose of the study}

The main aim of the present paper is to study the extent of development of digital maturity of the companies and of HRprocesses in the transport-logistics sector.

In last few years a good number of scientific and journalistic works have been published on the issues of digital economy. The attention of scientists to this phenomenon is constantly rising $[12,13,14]$.We agree with the view point of V.A. Plotnikov that not enough attention is being paid to the study of essence of digitization processes of the economy [15].We agree also with his view that the digital transformation must, first of all, lean on the key sectors of the economy, including the industry. There are no works devoted to study of specific problems of personnel management services in the digitization process. This poses difficulties in acceptance and realization of practical steps in digitally managed transformation of the existing economic model. For a successful transformation of a company into a digital one it is necessary to clearly understand the underlying problems on the part of personnel at every level and their clear interaction. In his expert interview Alexander Smirnov, Director of Data Science of Teradata, Russia emphasizes as follows: "One of the fundamental dangers here is the building of incorrect balance between the central office of digitization and initiatives taken by the local structured subdivisions or the subsidiary companies of the holding companies. The danger is that targeted and multidirectional initiatives to introduce digital technologies can lead to a loss of synergistic effect [11]. To overcome this danger, the systematic monitoring of the changes that are taking place, obtaining feedback from structural units and the construction of a fundamentally new system of organizational communications are necessary.

\section{MATERIALS AND METHODS}

The digitization processes in transport and logistics organizations can be appreciated with the help of objective indices: which program software is used by the personnel management services, speed of received data processing, what type of HR analytics is used by the company, what is the level of digital literacy of HR specialists, etc. But to understand the difficulties that come in the way of HR automation processes, to imagine the perspective directions of growth, can be possible only through an expert survey and study of the opinions of the authors of the given process.

Even more important is the subjective opinion of immediate participants of the process of digital transformation, with reference to understanding the extent of automation and integration of people management processes in this important sector of the economy. A sociological survey by the temporary creative team was conducted to define the key drivers of changes, possibilities and restrictions of the HR management systems of organizations, in the conditions of the digitization of economy in the framework of scientific project
RFBR № 19-010-01042\19. The first stage of the sociological survey was conducted among the specialists responsible for managing personnel in Russian organizations from 4th to 26th June 2019. The form consisted of 5 parts. A special attention was drawn to the part of questions directed towards finding and overcoming of barriers in the process of introduction of information digital technologies into the HR subdivisions of the organizations. The survey was conducted remotely with the aid of processing software GoogleDocs. Later on, the received data was processed with the aid of Excel program. In the present paper the survey results of only one of the respondent groups was analyzed, that is of employees of HR services in transport, logistics and distribution organizations ("distributio" from Latin- meaning organizing product sales, its distribution in the sales network). Among all the people surveyed the number of respondents representing transport, logistics and distribution organizations amount to 57 people: they represent more than 20 regions of Russia. $96.4 \%$ of respondents analyzed in the paper, have their company head offices in Russia. Every second respondent represents a medium business organization having 101 to 250 people. An equal number of $16.7 \%$ respondents, respectively, represent organizations having less than 15 people, having 16 to 100 people and having 1001 to 5000 people.

In accordance with the official affiliation, $43.75 \%$ of respondents were HR managers, heads of HR departments $41.67 \%$, HR partners, HR directors - $6.25 \%$ of respondents. By gender, respondents were divided as follows: women $60 \%$, men - 40\%. An overwhelming majority of people surveyed have higher education $-96.36 \%$; special secondary education and a science degree $-1.82 \%$ respectively.

$40 \%$ of the respondents have 3 to 10 years of working experience in personnel management services, and same figure is for respondents having more than 10 years. Almost same figure was for employees of HR groups who had from 1 year working experience and from 1 to 3 years.

$90.5 \%$ of respondents work in subdivisions called "personnel management", while $7.14 \%$ work in "HR management".

\section{RESULTS}

Problem 1. To determine the level of digital maturity of processes in transport, logistics and distribution organizations from the viewpoint of the HR specialists surveyed.

In the process of transformation from a traditional organization into a digital one, it goes through several stages, which differ in their degree of formation and maturity of automation processes in production and organizational processes. In the conditions of high level of maturity of digitalization in an organization we talk not only about the increase of productivity due to higher speeds of data processing, while converting to analog (or digital?) means of their transmission and optimization of business processes; rather about transformation of business processes, automation of management processes, change in business models of 
companies and formation of an ecosystem of a digital organization. The author of this paper O.S. Osipova, in the course of theoretical and methodological substantiation of sociological investigation program has suggested the following classification containing six levels of digital maturity of an organization, according to the extent and scale of penetration of automation processes into business processes of a company:

First level: Automation of operational management of the main (creating the main stream of income) business processes (CNC machines, computerization...).

Second level: Automation of operational management of the main and organizational management business processes (description of process, data base created in Excel etc.)

Third level: Automation of operational management of all types of business processes (main, management and supporting processes), for example: SRM, Directum, algorithms, internal- functional networking...)

Fourth level: Automation of operational and tactical management of all types of business processes (ERP systems, quality standard, standardization of processes- ISO, external client-oriented approach, inter- functional networking, corporate portals etc.)

Fifth level: Automation of operational, tactical and strategic management of all types of business processes based on information platforms (intranet, customization of clients' interests, external and internal functional client-oriented approach, interaction with stakeholders etc.)

Sixth level: Automation of operational, tactical and strategic management of all types of business processes based on intellectual platforms (connection of people and mechanisms to the Internet, automated data collection in real time, building of ecosystem, customization of stakeholders' interests etc.)

First to third levels of digitization cover operational level of organization management and differ among themselves in the extent of coverage of the main, management and supporting processes. Quite a detailed classification of automation of operational level of management is caused by the fact that most of Russian organizations are still in the beginning of digitization process, and their full and objective differentiation is needed. Later on, the first three levels of growth of digitization process can be merged into one for the convenience of analysis.

The fourth level of digitization proposes not only automation of operational management, but also of tactical management. The fifth and sixth levels of digitization cover automation of operational, tactical and strategic management. Both these levels differ in qualitative characteristics used by technical platform organizations, as well as in the level of involvement in the management process of the related parties and interacting subjects. Exactly these levels are associated with the term 'digital organization' in the minds of the respondents. It is exactly here that, in our view, it is correct to use the term 'digitization', which proposes optimization of processes and enhancement of interaction of the related parties, with the help of modern IT for the purpose of creating a better technological ecosystem.

The respondents were asked to evaluate the level of digital maturity of transformation of organizations which they represented. Practically, half of the respondents (49\%) noted that their organizations reached fourth level of digital transformation. However, every fourth person surveyed thinks that there is only operational management of main and organizational management processes in the organization. $15.7 \%$ of respondents placed their enterprise in the fifth level of digital maturity. According to Vasilii Nomokonov, a member of board of directors and executive director of LLC SIBUR - "Most digital initiatives in the industry are at this level of maturity - these are not IT projects in true sense, but complex organizational projects with an IT component, proposing building of cross functional networking and a proper management of changes." [16].

Problem 2. To determine the extent of maturity of HR processes

For understanding the maturity of automation of HR processes and in order to compare the data collected during our sociological survey, with the results of the investigation in Russia by SAP company in collaboration with Deloitte at the end of 2018, we used the four-level classification of maturity of HR processes. This classification includes the following levels:

First level: HR on paper - processes are made manually with the help of basic computer programs on PC. HR processes are not structured.

Second level: Fragmented automation - processes are automated, but in varying degrees and almost in an unrelated manner with each other; a lot is still done manually; different computer software for different processes; data is stored in different places; customization (individualization) is done 'manually' by revision; scaling is difficult.

Third level: Mature automation - processes are related, simplified and standardized; customization by tuning and not by revision; mobile access from any device; single entry point; single data platform; building of cloud HR platform with mobile applications (Human Resource Information SystemsHRIS).

Fourth level: Intellectual HR - machine learning; intellectual opportunities; predictive analytics; permanent optimization; VR/AR; single interface along many applications.

Only $16.36 \%$ of the respondents think that mature automation is present in their organizations. Majority of respondents: $70.91 \%$ mentioned fragmented automation which is present in their organizations. The level of automation of HR processes in transport logistical organizations is lower 
than the level of automation of main business processes. At the same time the respondents highly appreciated level of integration of main HR processes. $88.5 \%$ of respondents mentioned that all the main HR processes are consolidated and only $11.5 \%$ of respondents think that integration has not begun yet. This index is much higher (more than by $30 \%$ ) than the total among all the HR specialists surveyed up to $26^{\text {th }}$ June 2019.

$90.2 \%$ of the respondents noted that a strategy of working with personnel in their organizations has been developed and is being implemented, $5.9 \%$ of respondents said that the strategy is being developed and $3.92 \%$ of respondents have not thought about it yet. As per their opinion work on the strategy of growth of the HR system/ personnel management system is less encouraging. Almost two thirds of respondents noted that the strategy has been developed and is carried out $64.7 \%$; as per every fourth answer the strategy of growth of the personnel management system in an organization is in a development stage- $23.53 \%$. $11.76 \%$ of respondents found it difficult to reply this question.

In every third organization the automation of $\mathrm{HR}$ processes continues from 1 to 3 years. In an overwhelming majority of transport and logistical organizations which took part in the survey, automation of HR processes has a longer history: from 3 to 5 years $-28.57 \%$; from 6 to 10 years $-12.24 \%$; more than 10 years- $18.37 \%$. In $92 \%$ of cases the joint project group is responsible for the automation of HR processes in the organizations represented by the respondents. This group includes IT and HR specialists. Only in $5.26 \%$ of cases the HR subdivision is responsible.

The nature of the digital HR strategy in their organizations was appreciated in a restrained manner by the respondents. To the question: 'How would you characterize the digital HR strategy in your company?' $64.4 \%$ replied that it is restrained in nature, and can be executed by introducing different software products and market trends. Only $6.67 \%$ noted its aggressive nature: companies are ready to invest in digital technology more than their competitors, and are keen to switch over to the platform model.

It was also studied in the course of survey how the process of adoption of digital technology in HR subdivisions of organizations was carried out, their correctness, and effectiveness of completion of certain HR functions with the help of software programs. An interesting fact is that employees of HR subdivisions learnt the software quite quickly, which they worked upon at the moment of the sociological survey. $64 \%$ of respondents needed 1 month to learn the software, $32 \%$ needed up to 3 months and only $4 \%$ up to 6 months. $36.6 \%$ noted that learning new software had a positive effect on the interaction between the employees of HR subdivision: they came together for solving new tasks.

Problem 3. Comparative analysis of the respondents' opinion about digital transformation in the logistics and transport sector

On the whole, the results of the survey have shown a higher level of integration of HR processes, high penetration of strategic approach in the work with personnel in the transport and logistics sector. It can be assumed that this is due to specificity of organization of business processes in transport and logistics economic sector. Almost all respondents who were HR specialists in transport and logistics companies noted that automation of HR processes is more relevant in much diversified and large international companies, as compared to virtual organizations. Their opinion significantly differs from the replies of majority of HR specialists surveyed.

A separate section in the survey form was devoted to the future of digital organization in HR services. Unfortunately, the limited space of this paper does not permit us to present the results obtained.

\section{DISCUSSION}

As it was noted earlier, the potential of the transport logistics sector is high from the point of view of development of digitization and emergence of digital organizations. The introduction of IoT technologies in logistics allows solving such relevant tasks in this field as reducing the expenses for cargo carriers and delays on the way. Also, it allows to increase transparency of transportations (including help of RFID marks), and minimize the influence of human factor. Internet connected motor transport and remote monitoring of auto depots allows minimizing operational expenses due to repair optimization and equipment maintenance. Besides, "Uberization" of cargo carriers is widely spread, which makes it possible to refuse services of dispatch companies. The economic effect of IoT introduction into logistics is estimated to be 542 billion Rubbles up to the year 2025 [6].

The results of the survey have shown that as of now, very few transport and logistics enterprises proceeded to the fifth and sixth levels of digital maturity, proposing use of Internet of the second generation in full volume of its potential. The net means a lot for realization of enterprise's plans as it does not only create conditions, in the first place, for the further general automation of the production and organizational processes, in the matter of data collection and processing, but it also gives everything needed for the development and customization of HR analytics and raising efficiency of work of the services responsible for dealing with people.

One of the key questions is the following: "How the automated information system of HR management processes should be built up in companies?" All HR specialists surveyed think that in the long term the automation in organizations should be carried out constantly, without waiting till technical means would impede work of HR subdivision. $78.2 \%$ of respondents are ready to improve their digital literacy as per the necessity; moreover $21.8 \%$ expressed their readiness to do it even at their own expense. $82.35 \%$ respondents noted that a single system is required which will unite all HR processes and only $17.65 \%$ think that as HR processes are different and their owners solve different tasks, that is why it is desirable to have specialized software products.

All the respondents think that the automation processes of HR processes must continuously happen on the basis of step by 
step realization of smaller projects and their integration within the framework of a developed HR- strategy. It is a mutually supportive project team consisting of IT and HR professionals that must be responsible for the automation of HR processes, because they have a varied set of competence (82.98\%). Only $4.26 \%$ of surveyed persons think that it is the HR project teams as being the main functional customers, which must realize automation of HR processes. As it was revealed in the process of investigation, that there are difficulties in the transition to more mature levels of digital transformation, it is necessary to conduct additional investigations with the purpose of working out the methodical recommendations.

\section{CONCLUSION}

Digitalization process in transport and logistics organizations is not uniform. Almost every second respondent placed his/her enterprise in the fourth level of digital maturity, which is a good enough average index in the country. But clearly, it is not good enough in the increasing international competition. Today new technologies have changed the image of personnel management. HR services in the transport logistics sector to a large extent are ready for further digital transformation, though the level of digital integration of HR services themselves is still lower than the digital acceleration of production on the whole. Digital maturity cannot be achieved without the building of own technological platforms, usage of IT architecture of the new generation. The respondents noted that for the growth of transport logistics sector a single system is required, which can unite all the HR processes. Actually, they have voted for an architectural approach for the growth of network. HR services employees are psychologically ready to enhance their digital competence, even at the cost of investing their own sources into professional refresher courses. The present study has confirmed that among the executive level and HR specialists there is an increasing understanding that the specific technologies do not guarantee a shift to the next level of growth and effectiveness. For the fourth industrial revolution, the key role lies in the extent of integration into socioeconomic and working relations, and not in a set of separate technologies.

\section{REFERENCES}

[1] Decree of the President of the Russian Federation dated 09/05/2017 No. 203: "On the strategy of the development of Information-based society in the Russian Federation for the years 2017 - 2030", [electronic source]:

http://www.garant.ru/products/ipo/prime/doc/71570570/\#ixzz5amJaozL $\mathrm{Z}$ (consulted on 05.07.2019)

[2] Order of the Government of the Russian Federation dated 28/07/2017 N 1632-r: "On affirmation of the program "The digital economy of the Russian Federation"'K. Elissa, "Title of paper if known," unpublished.

[3] Order of the Government of Moscow dated 11/10/2010 N 2215-RP "On the Concept of making available to the residents of the City of Moscow telecommunication services in order to receive socially relevant information by creating conditions for equal access to cable TV and internet resources",[electronic source]: https://official.academic.ru/29422 (consulted on 04.07.2019)

[4] Kerravala Zevs, 10 major principles for constructing network for digitization. ZK Research: Subdivision of Kerravala Consulting, February 2016 [electronic source]. https://www.cisco.com/c/dam/global/ru_kz/solutions/enterprisenetworks/digital-network-architecture/pdf/nb-04-dna-zkresearch_10_networking_priorities-cte-ru.pdf/_ (consulted on 05.07.2019)

[5] Notice SAP Forum, Moscow 2017 [electronic source]: http://events.sap.com/ru-sap-forum-moscow-2017/ru/agenda (consulted on 05.07.2019).

[6] Internet of Things, IoT, M2M market of Russia. Catalogue of IoT systems and projects/ Investigation by PwC (IoT) in Russia, Summer, 2017 [electronic source]: http://www.tadviser.ru/index.php/ Статья:Интернет_вещей,_IoT,_M2M_(рынок_России (consulted on 05.07.2019)

[7] O.Osipova, A. Artamonov, "Labor Stimulation in Systemically Important Banks within the Conditions of Economic Crisis and Sanctions", Proceedings of the 30th International Business Information Management Association Conference, IBIMA 2017 - Vision 2020: Sustainable Economic development, Innovation Management, and Global Growth, Madrid Spain: International Business Information Management Association (IBIMA), 2018, pp. 1001-1009.

[8] Nathan Sloan, Dimple Agarwal, Stacia Garr, Karen Pastakia Performance management: Playing a winning hand 2017 Global Human Capital Trends, February 28, 2017 [electronic source]: https://www2.deloitte.com/insights/us/en/focus/human-capitaltrends/2017/redesigning-performance-

management.html?id=us:2el:3dc:dup3821:awa:cons:hct17 (consulted on 05.07.2019).

[9] Tech Trends 2019 [electronic source]: https://www2.deloitte.com/content/dam/insights/us/articles/TechTrends-2019/DI_Tech Trends2019.pdf pp.142 (consulted on 06.07.2019).

[10] Industrial Internet of Things in Russia. Investigation of T Adviser and GK "Rostech" [electronic source]:

http://www.tadviser.ru/index.php/Статья:IIoT_2018:_Рынок_промышл енного_интернета_вещей_в_России (consulted on 23.05.2019)

[11] Alexander Smirnov, Matters of round table conference "The future is here. Nuances of digitization of the economy", Gazpromneft 2018, No. 5 [electronic source]: https://www.gazprom-neft.ru/press-center/sibneftonline/archive/2018-may/1589541/ (consulted on 05.06.2019)

[12] A.V.Babkin, D.D.Burkal'tseva, D.G.Kosten', Yu.N.Vorob'ev, “The formation of digital economy in Russia: essence, special features, technical normalization, and problems of development," Scientific and Technical Journal of St. Petersburg State Polytechnic University: Economic Sciences 2017, vol.10, No.3, pp. 9 - 25.

[13] Yu.V.Vertakova, T.O.Tolstykh, E.V.Shkrupeta, V.V.Dmitrieva, Transformation of managed systems under the impact of digitization of economy, Monograph, Kursk, Izdvo YUZGU 2017, pp.156.

[14] Digital Economy and Industry 4.0: New Challenges: Proceedings of a Scientific and Practical Conference with International Participation / Ed. A.V. Babkina, St. Petersburg: Publishing House Polytechnic University, 2018, pp.573.

[15] V.A.Plotnikov," Digitization of production: theoretical essence and future prospects of development of Russian economy News of St. Petersburg State University of Economics, 2018, No.4, pp. 16-24 .

[16] Vasilii Nomokonov, Matters of round table conference "The future is here. Nuances of digitization of the economy", Gazpromneft 2018, No.5 [electronic source]: https://www.gazprom-neft.ru/press-center/sibneftonline/archive/2018-may/1589541/ (consulted on 05.07.2019) 